SUPPORTING INFORMATION

\title{
Sulfolane-Induced Supercharging of Electrosprayed Salt Clusters: An Experimental/Computational Perspective
}

\author{
Leanne M. Martin and Lars Konermann* \\ Department of Chemistry, The University of Western Ontario, London, Ontario, \\ N6A 5B7, Canada.
}

* corresponding author: konerman@uwo.ca

This file contains:

Figure S1. MD temporal profiles for droplets with different initial NaI stoichiometries. 

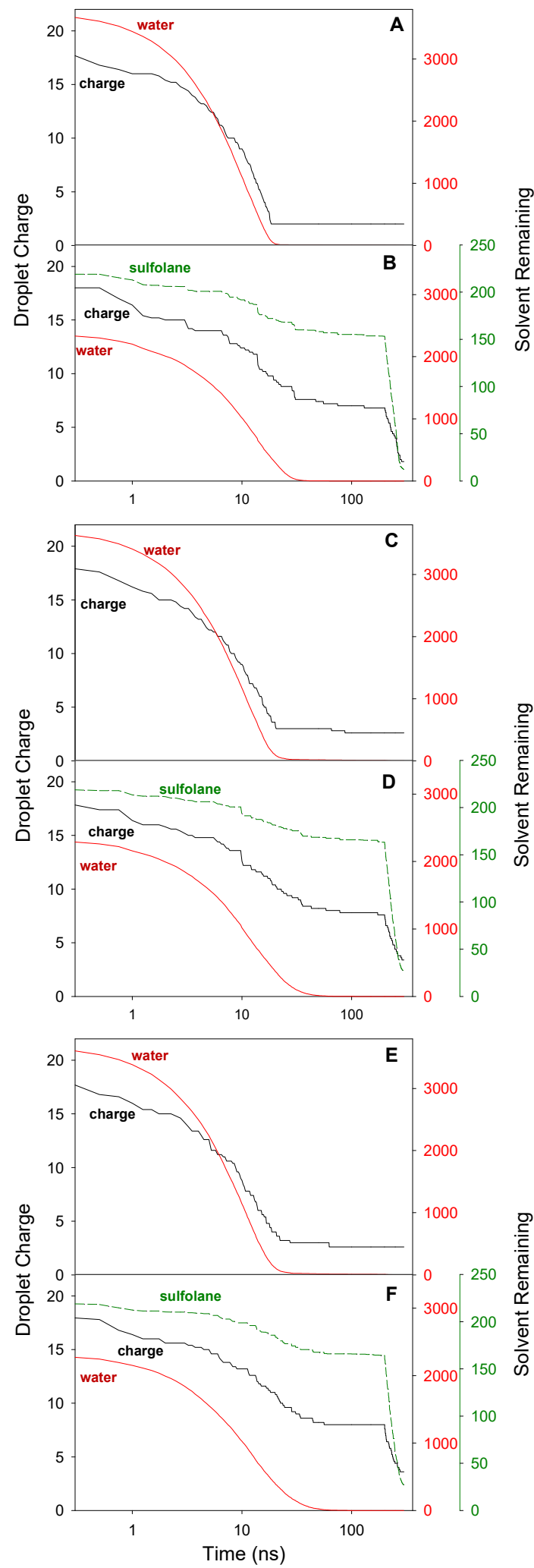

Figure S1. MD data, depicting changes of various droplet components over time for water $(\mathrm{A} / \mathrm{C} / \mathrm{E})$ and water/sulfolane droplets $(\mathrm{B} / \mathrm{D} / \mathrm{F})$. The initial droplets contained $(\mathrm{A}, \mathrm{B}) 26 \mathrm{Na}^{+} / 8 \mathrm{I}^{-},(\mathrm{C}, \mathrm{D}) 48 \mathrm{Na}^{+} /$ $30 \mathrm{I}^{-}$, and (E,F) $58 \mathrm{Na}^{+} / 40 \mathrm{I}^{-}$. 